\title{
ANALISIS TINGKAT KEPUASAN KONSUMEN TERHADAP KUALITAS PELAYANAN DI KLINIK PERMATA BUNDA RENGAT
}

\author{
Elza Rachman Panca Priyanda, Oktri Lestari, Riri Amanda Fitriana, Futri \\ Handayani, Ayu Dwi Utami \\ Pharmacy Major, Sekolah Tinggi Ilmu Kesehatan Har-Kausyar, Indragiri Hulu, \\ Indonesia \\ Email: ezarachman9@gmail.com,oktrilestari.ol@gmail.com, \\ ririamanda.fit@gmail.com, futrihandayani89@gmail.com, \\ ayudwi.utami09@gmail.com
}

\begin{abstract}
Abstrak
Pelayanan adalah hal penting yang menjadi bukti jaminan kepuasan pasien, hal ini juga sudah menjadi salah satu hal utama yang menentukan kualitas sebuah pelayanan. Penelitian ini bertujuan untuk menganalisis kepuasan konsumen terhadap kualitas pelayanan di klinik permata bunda. kepuasan pasien dengan pelayanan merupakan variabel penting untuk menilai jaminan kepuasan pasien telah digunakan sebagai indikator kualitas pelayanan sebagai sarana untuk mengidentifikasi pasien yang memiliki nilai lebih tinggi atau kemungkinan kepatuhan yang lebih rendah dengan program pengobatan, dan sebagai tolak ukur untuk menilai daya saing pasar. Teknik pengumpulan data menggunakan angket yang disebar melalui media google form. Data dianalisis menggunakan statistik uji chi-square. Berdasarkan hasil penelitian $90 \%$ menyatakan puas terhadap pelayanan di Klinik Permata Bunda. Kepuasan pelayanan pasien rawat jalan terdistribusi secara menyeluruh dengan mayoritas termasuk pada kategori puas. Indikator tingkat kepuasan pasien tidak ada perbedaan berdasarkan berdasarkan karakteristik Jenis kelamin, Usia, dan Pekerjaan. Dalam penelitian yang telah dilakukan mayoritas konsumen/pasien yang berobat di Klinik Permata Bunda menyatakan kepuasan yang tinggi pada variabel ketanggapan dan masih ada variabel yang masuk kedalam kategori tidak puas.
\end{abstract}

Kata Kunci: analisis kepuasan; pasien rawat jalan; klinik permata bunda

\section{Abstract}

Service is an important thing that is a proof of patient satisfaction assurance, it has also become one of the main things that determine the quality of a service. Patient satisfaction with service is an important variable for assessing patient satisfaction assurance has been used as an indicator of service quality as a means to identify patients who have higher value or lower likelihood of compliance with treatment programs, and as a benchmark for assessing market competitiveness. Data collection techniques use questionnaires distributed through google form media. The data is analyzed using chi-square test statistics. Based on the results of the study, 90\% expressed satisfaction with the service at Permata Bunda Clinic. Outpatient service satisfaction is distributed thoroughly with the majority including the satisfied category. Indicators of patient satisfaction levels made no difference

$\begin{array}{ll}\text { How to cite: } & \text { Priyanda, E. R. P., (2021) Analisis Tingkat Kepuasan Konsumen Terhadap Kualitas Pelayanan Di Klinik } \\ & \text { Permata Bunda Rengat. Syntax Idea, 3(9), https://doi.org/10.36418/syntax-idea.v3i9.1460 } \\ \text { E-ISSN: } & \text { 2684-883X } \\ \text { Published by: } & \text { Ridwan Institute }\end{array}$


based on characteristics of gender, age, and occupation. In research that has been conducted by the majority of consumers / patients who seek treatment at Permata Bunda Clinic expressed high satisfaction in the budget variable and there are still variables that fall into the category of dissatisfaction.

Keywords: satisfaction analysis; outpatients; mother gem clinic

Received: 2021-08-22; Accepted: 2021-09-05; Published: 2021-09-20

\section{Pendahuluan}

Kepuasan pasien dengan pelayanan merupakan variabel penting untuk menilai jaminan kepuasan pasien telah digunakan sebagai indikator kualitas pelayanan sebagai sarana untuk mengidentifikasi pasien yang memiliki nilai lebih tinggi atau kemungkinan kepatuhan yang lebih rendah dengan program pengobatan, dan sebagai tolak ukur untuk menilai daya saing pasar (Yuniar \& Handayani, 2016). Namun, kuesioner multi-item yang panjang mungkin mahal dan memakan waktu lama untuk diselesaikan, yang mengakibatkan berkurangnya kepatuhan pasien dan klinisi. Dengan demikian, ukuran kepuasan pasien dengan perawatan yang berguna secara klinis harus relatif ringkas, mudah dan murah untuk dikelola, berisi item yang sesuai, dan secara psikometris masuk akal (Horvat \& Kos, 2010).

Alat yang berguna dari ukuran kepuasan pasien adalah kemampuan untuk membedakan antara berbagai faktor yang mempengaruhi kepuasan (Winanto, 2013) Misalnya, seorang pasien mungkin sangat puas dengan interaksinya dengan terapis, tetapi mungkin tidak puas dengan proses penerimaannya. Kemampuan suatu ukuran untuk mencerminkan perbedaan-perbedaan ini dikenal sebagai validitas diskriminan. Selama pengembangan kuesioner, validitas diskriminan seringkali awalnya dinilai dengan melakukan berbagai jenis analisis faktor eksplorasi (yaitu, uji statistik yang menyarankan "faktor" atau kelompok item yang berkorelasi dalam kuesioner) (Hasan et al., 2013). Pasien akan merasa puas jika pelayanan yang diberikan telah sesuai dengan apa yang diharapkan oleh mereka dan memenuhi standard. Namun jika rumah sakit memberikan pelayanan yang belum sesuai dengan apa yang diharapkan pasien maka pasien akan merasa tidak puas (Risnandi, 2014). Ketidakpuasan pasien tersebut berakibat dengan menurunnya angka pasien yang akan menggunakan layanan di rumah sakit itu, dengan kata lain pasien memilih untuk menggunakan rumah sakit yang lain sehingga perlu adanya perbaikan yang pada dasarnya tertuju pada kualitas pelayanan karena kepuasan pasien sangat erat kaitannya dengan kualitas (Sampurno, 2008). Angket merupakan alat ukur yang dibuat untuk melihat kepuasan pasien dalam upaya meningkatkan kunjungan pasien serta perlu dilakukan evaluasi kepuasan pasien terhadap pelayanan pasien rawat jalan di rumah sakit.

Kepuasan pasien sangat penting maka dari itu dilakukan survei dan perlu dengan melakukan secara bersamaan pengukuran kriteria mutu pelayanan kesehatan yang ada pada rumah sakit tersebut. Menurut (Pohan, 2007), ekonomi pasti mengalami transformasi dan secara tidak langsung itu mengubah keinginan dan kebutuhan 
Elza Rachman Panca Priyanda, Oktri Lestari, Riri Amanda Fitriana, Futri handayani, Ayu Dwi Utami

masyarakat terhadap pelayanan pasien. Oleh karena itu, kepuasan pasien perlu diukur secara continue dan akurat. Dimensi kualitas pelayanan terdiri dari: kehandalan, ketanggapan, jaminan kepastian, perhatian dan wujud nyata. Semua dimensi itu merangkum secara garis besar kualitas pelayanan yang digunakan untuk mengukur kepuasan pasien dalam memperoleh pelayanan kesehatan yang diberikan oleh rumah sakit (Aritonang \& Lerbin, 2005).

Penelitian terkait pernah dilakukan dengan tema Analisis Tingkat Kepuasan Pasien Rawat Jalan terhadap Kualitas Pelayanan (Studi Kasus: RSU Bhakti Asih Tangerang) menyatakan bahwa ketepatan dokter mendiagnosa penyakit, keamanan lingkungan rumah sakit, kelengkapan obat-obatan di apotek, dan kelengkapan fasilitas peralatan modern perlu ditingkatkan (Aryani, Husnawati, Muharni, \& Afrianti, 2015). Sedangkan (Hardi, 2010) mengatakan bahwa kepastian jam pelayanan dan perhatian individual kepada pasien perlu ditingkatkan, selain itu RSUD Pasaman Barat juga harus melakukan pemeliharaan peralatan kesehatan seperti tempat tidur pasien dan tenaga kesehatan serta mengganti peralatan yang tidak layak pakai, petugas diharapkan untuk meningkatkan koordinasi dan komunikasi sesama petugas. dalam penelitian yang dilakukan di RSK. ST Vincentius A Paulo Surabaya (RKZ) menunjukkan hasil pengukuran gap dengan metode Servqual yang diberikan layanan farmasi RKZ masih belum memenuhi harapan pasien, karena nilai kepuasan pasien terhadap layanan farmasi masih lebih rendah daripada nilai harapan (Harijono \& Soepangkat, 2011). Belum ada penelitian terkait yang meniliti kepuasan pasien di Klinik Permata Bunda Rengat.

\section{Metode Penelitian}

Penelitian yang dilakukan oleh peneliti merupakan penelitian jenis deskriptif observasi, dengan melakukan rancangan penelitian cross sectional dimana pengumpulan data untuk penelitian ini dilakukan dengan mengumpulkan google form di waktu yang sama sesuai dengan deadline yang diberikan. Penelitian ini dilakukan di Klinik Permata Bunda. Pengambilan data dilakukan pada bulan Juni-Juli 2021. Populasi dalam penelitian ini adalah seluruh pasien yang mendapatkan pelayanan dari Klinik Permata Bunda pada bulan Juni - Juli 2021. Sampel adalah bagian populasi yang memenuhi kriteria inklusi dengan metode purposive sampling. Besarnya sampel berdasarkan rumus (Smith, Maharaj, \& James, 2011) diketahui bahwa besar populasi penelitian adalah 100 pasien dan tingkat kepercayaan yang diinginkan adalah 10\%, maka jumlah minimal sampel penelitian adalah 10 orang. Pada pelaks anaan penelitian jumlah sampel yang diamati sebanyak 20 orang.

Pengolahan data dilakukan dengan tahapan pengeditan, pemasukkan data, pengkodean, pembersihan. Serangkaian bentuk penghitungan paling dasar dari teknik analisis data statistik. Jika data hanya berisi satu variabel dan tidak berhubungan dengan sebab atau akibat hubungan, teknik analisis univariat digunakan dan analisis untuk menyelidiki hubungan antara dua kumpulan data, dengan sepasang pengamatan yang diambil dari satu sampel atau individu, misalnya hubungan antara kekuatan 
cengkeraman dan kekuatan individu disebut analisis bivariat yang menggunakan Uji Chi-square (Mumu, 2015). Variabel ketanggapan, meliputi ketanggapan petugas klinik untuk melayani resep konsumen, ketepatan informasi obat yang diberikan petugas klinik, dan waktu tunggu pelayanan obat. Variabel kehandalan meliputi kemudahan tata kelola dalam menebus obat. Variabel jaminan meliputi keutuhan obat yang didapat berdasarkan resep, dan keringanan konsumen mengenali petugas dengan adanya tanda pengenal pelayan (Sari, 2014). Variabel keramahan meliputi keramahan pelayanan dalam memberikan pelayanan resep. Variabel bukti fisik meliputi akses lokasi klinik mudah ditemui dan terjangkau, kecukupan sarana prasarana, khususnya tempat duduk konsumen di ruang tunggu, kenyamanan dan kebersihan ruang tunggu, ketersediaan tempat untuk pelayanan resep dan Ketersediaan akses penunjang untuk pasien: cuci tangan, WC, air minum, brosur obat, atau timbangan berat dan lain-lain.

\section{Hasil dan Pembahasan}

Jumlah narasumber/ konsumen yang diteliti sebanyak 20 konsumen. Hasil identifikasi masing-masing konsumen yang dapat dilihat pada Tabel 1. Identifikasi konsumen di Klinik Permata Bunda mayoritas berada pada kelompok umur 40-59 tahun, jenis kelamin wanita, pendidikan tingkat menengah, tidak bekerja/ibu rumah tangga.. Pembagian kepuasan konsumen rawat jalan sesuai dengan variabelnya dapat dilihat pada Tabel 2. Kepuasan pasien terhadap pelayanan kesehatan di klinik Permata Bunda 90\%. Skor tertinggi kepuasan pasien dalam pelayanan kesehatan adalah pada variabel kehandalan dan skor terendah pada variabel bukti fisik, yaitu ketersediaan akses penunjang untuk pasien seperti (tempat cuci tangan, WC, air minum, brosur obat, timbangan berat atau lainnya) dan kecukupan sarana prasarana khususnya tempat duduk di ruang tunggu Klinik Permata Bunda.

Tabel 1

Identifikasi Konsumen di Klinik Permata Bunda Pada Tahun 2021

\begin{tabular}{lcc}
\hline \multicolumn{1}{c}{ Karakteristik Pasien Rawat } & \multicolumn{2}{c}{ Klinik Permata Bunda } \\
\cline { 2 - 3 } & Jumlah & \% \\
\hline Umur: & 5 & $25 \%$ \\
Kurang dari 40 Tahun & 13 & $65 \%$ \\
40-59 Tahun & 2 & $10 \%$ \\
60 Tahun Keatas & & \\
Jenis kelamin: & 2 & $10 \%$ \\
Laki-Laki & 18 & \\
Perempuan & & \\
Pendidikan: & & $100 \%$ \\
Tidak/lulus SMP & 20 & $10 \%$ \\
Lulusan SMA keatas & & $75 \%$ \\
Pekerjaan: & 2 & $15 \%$ \\
Pelajar & 15 & \\
Pekerja & 3 & \\
Tidak/ belum bekerja & & \\
\end{tabular}


Elza Rachman Panca Priyanda, Oktri Lestari, Riri Amanda Fitriana, Futri handayani, Ayu Dwi Utami

Tabel 2

Kepuasan Pasien Rawat Jalan Klinik Permata Bunda Pada Tahun 2021

\begin{tabular}{ccc}
\hline Pernyataan Tentang Kepuasan & \multicolumn{2}{c}{ Klinik Permata Bunda } \\
\cline { 2 - 3 } & \multicolumn{2}{c}{ Puas $\quad$ KurangPuas } \\
\hline
\end{tabular}

Variabel ketanggapan:

Kelihaian Pelayanan terhadap resep

pasien

Ketepatan informasi obat yang diberikan

Wait list pelayanan obat dimulai saat obat

diberikan sampai diterima tidak lama.

Variabel kehandalan:

Kemudahan administrasi menebus obat

Variabel jaminan:

Kecukupan obat yg diperoleh

berdasarkan resep Keringanan mengenali

petugas

Variabel keramahan:

Keramahan petugas dalam pelayanan resep

\section{Variabel bukti fisik:}

Lokasi mudah dikenal dan terjangkau

Kecukupan tempat duduk di ruang tunggu Kenyamanan dan kebersihan ruang tunggu

Kecukupan tempat untuk pelayanan resep

Kecukupan akses penunjang untuk pasien: air minum, brosur obat, atau

$90 \% \quad 10 \%$

$98 \% \quad 2 \%$

$90 \% \quad 10 \%$

$90 \% \quad 10 \%$

timbangan badan, dll.

\section{Rerata}

$90 \%$

$90 \%$

$10 \%$

$80 \%$

$10 \%$

$85 \%$

$15 \%$

$91 \%$

$9 \%$

$80 \%$

$20 \%$

Penelitian yang dilakukan di Klinik Permata Bunda Rengat di tahun 2021 mendapati hasil bahwa 90\% konsumen merasa puas dengan pelayanan klinik dan $10 \%$ konsumen mengatakan tidak puas terhadap pelayanan Klinik. Variabel bukti fisik mempunyai tingkat kepuasan terendah dan variabel ketanggapan mempunyai tingkat kepuasan tertinggi. Berdasarkan Tabel. 2 kepuasan pasien pada variabel bukti fisik yang menjadi prioritas untuk segera dievaluasi adalah kemudahan akses penunjang untuk pasien, ruang tunggu pasien tertata rapi, kecepatan dan ketepatan menemukan dokumen rekam medis dan keramahan pelayan melayani konsumen Klinik (Faramita \& Wiyanto, 2016).

Budiman dkk, telah melakukan penelitian dan mendapati hasil terkait kepuasan pasien dari Variabel terhadap pelayanan jamkesmas di wilayah Puskesmas Tanjungsari Kabupaten Bogor adalah sebesar 81,0\% (Budiman S, 2010).

Tingkat kesesuaian antara harapan dan kenyataan dengan Variabel keseluruhan Kepuasan pelayanan adalah $79,70 \%$. Sedangkan tingkat ketepatan tiap-tiap variabel meliputi wujud/tampilan $81,94 \%$, kehandalan 79,36\%, Daya tanggap 77,0\%, 
Jaminan 79,44\% dan empati 80,88\%.9 (Einurkhayatun, Suryoputro, \& Fatmasari, 2017). Hasil penelitian Veicy F. Gaghana menyatakan bahwa pelayanan kesehatan di Puskesmas Tuminting melihatkan hasil bahwa 50,9\% puas terhadap kehandalan, $54,7 \%$ puas terhadap daya tanggap, $77,4 \%$ puas terhadap jaminan, 55,7\% puas terhadap perhatian, $66 \%$ puas terhadap bukti fisik kepada pasien BPJS sesuai dengan urutan yang paling tinggi dalam memuaskan pasien yaitu jaminan, bukti fisik, perhatian, ketanggapan, dan kehandalan (Gaghana, Siagian, Palandeng, \& Monintja, 2014).

Koratiwida telah melakukan penelitian terhadap pasien rawat jalan di Rumah Sakit di Jakarta menunjukkan perempuan mempunyai hubungan yang erat dengan kepuasan terhadap pelayanan obat di Rumah Sakit (Kurniawan \& Intiasari, 2012) Pasien rawat jalan dengan pengetahuan baik memiliki kepuasan sebesar 1,528 kali dibandingkan pasien dengan pengetahuan cukup (Putria, Maula, \& Uswatun, 2020), Tidak ada hubungan bermakna antara karakteristik (umur, jenis kelamin, pendidikan, pekerjaan, jenis pembiayaan) dan kepuasan pasien di RS Semarang (Sriatmi, Suryawati, \& Hidayati, 2014).

Sesuai dengan penelitian terdahulu yang dilakukan oleh beberapa peneliti/ahli, maka dapat dilihat bahwasannya tingkat kepuasan di setiap rumah sakit/klinik itu berbeda, karena setiap individu memiliki ciri khas tersendiri dan setiap rumah sakit memiliki keunggulannya masing-masing (Supartiningsih, 2017).

\section{Kesimpulan}

Kepuasan pasien rawat jalan terhadap pelayanan Klinik Permata Bunda 90\%. Persentase terbesar pasien rawat jalan di Klinik Permata Bunda adalah pada kelompok umur 40-59 tahun, jenis kelamin perempuan, pendidikan lanjutan, bekerja. Dalam penelitian yang telah dilakukan mayoritas konsumen/pasien yang berobat di Klinik Permata Bunda menyatakan kepuasan yang tinggi pada variabel ketanggapan dan masih ada variabel yang masuk kedalam kategori tidak puas. 
Elza Rachman Panca Priyanda, Oktri Lestari, Riri Amanda Fitriana, Futri handayani, Ayu Dwi Utami

\section{BIBLIOGRAFI}

Aritonang, Lerbin R., \& Lerbin, R. (2005). Kepuasan pelanggan. Gramedia. Jakarta.

Aryani, Fina, Husnawati, Husnawati, Muharni, Septi, \& Afrianti, Richa. (2015). Analisa Kepuasan Pasien Rawat Jalan Terhadap Kualitas Pelayanan Di Instalasi Farmasi Rumah Sakit Islam Ibnu Sina Pekanbaru. PHARMACY: Jurnal Farmasi Indonesia (Pharmaceutical Journal of Indonesia), 12(1). Google Scholar

Budiman S, Herlina N. (2010). Hubungan status demografi dengan kepuasan masyarakat tentang pelayanan Jam kesmas di wilayah Puskesmas Tanjungsari Kabupaten Bogor Tahun 2010. Jurnal Kesehatan Kartika., 1-17.

Einurkhayatun, Biyanda, Suryoputro, Antono, \& Fatmasari, Eka Yunila. (2017). Analisis tingkat kepuasan pasien terhadap kualitas pelayanan rawat jalan di Puskesmas Duren dan Puskesmas Bergas Kabupaten Semarang tahun 2017. Jurnal Kesehatan Masyarakat (Undip), 5(4), 33-42. Google Scholar

Faramita, Nanditya Ika, \& Wiyanto, Satra. (2016). Penyebab dan Solusi Lama Waktu Tunggu Pelayanan Obat di Instalasi Farmasi Rawat Jalan Rumah Sakit. Jurnal Kedokteran Brawijaya, 29(3), 245-251. Google Scholar

Gaghana, Veicy F., Siagian, Iyone E. T., Palandeng, Henry M. F., \& Monintja, Tyrsa. (2014). Tingkat kepuasan pasien Universal Coverage terhadap pelayanan kesehatan di Puskesmas Tuminting Manado. Jurnal Kedokteran Komunitas Dan Tropik, 2(1). Google Scholar

Hardi, John. (2010). Analisis tingkat kepuasan pasien umum dan pasien jamkesmas terhadap mutu pelayanan rawat inap di RSUD Pasaman Barat tahun 2010. Universitas Andalas. Google Scholar

Harijono, Hilda, \& Soepangkat, Bobby Oedy P. (2011). Upaya peningkatan kualitas layanan farmasi Rsk. St Vincentius A Paulo Surabaya dengan menggunakan metode servqual dan QFD. Prosiding Seminar Nasional Manajemen Teknologi XIV Program Studi MMT-ITS, Surabaya, 23. Google Scholar

Hasan, Sanah, Sulieman, Hana, Stewart, Kay, Chapman, Colin B., Hasan, Mohammed Yousif, \& Kong, David C. M. (2013). Assessing patient satisfaction with community pharmacy in the UAE using a newly-validated tool. Research in Social and Administrative Pharmacy, 9(6), 841-850. Google Scholar

Horvat, Nejc, \& Kos, Mitja. (2010). Development and initial validation of a patient satisfaction with pharmacy performance questionnaire (PSPP-Q). Evaluation \& the Health Professions, 33(2), 197-215. Google Scholar

Kurniawan, Arif, \& Intiasari, Arih Diyaning. (2012). Pengaruh Karakteristik Pasien Terhadap Indeks Kepuasan Masyarakat Tentang Pelayanan Rawat Jalan Puskesmas Banyumas. Kesmas Indonesia, 5(2), 169-179. Google Scholar

Mumu, Like J. (2015). Analisis faktor-faktor yang berhubungan dengan kepuasan pasien di Poliklinik Penyakit Dalam RSUP Prof. Dr. RD Kandou Manado. JIKMU, 
5(4). Google Scholar

Pohan, I. S. (2007). Jaminan Mutu Layanan Kesehatan, Edisi Kedua. Jakarta: Buku Kedokteran. Google Scholar

Putria, Hilna, Maula, Luthfi Hamdani, \& Uswatun, Din Azwar. (2020). Analisis Proses Pembelajaran dalam Jaringan (DARING) Masa Pandemi Covid- 19 Pada Guru Sekolah Dasar. Jurnal Basicedu, 4(4), 861-870. Google Scholar

Risnandi, C. (2014). Faktor-Faktor Yang Berhubungan Dengan Kepuasan Pasien Rawat Jalan Di Puskesmas Lingga, Kabupaten Kubu Raya [skripsi]. Jakarta: STIK St. Carolus. Google Scholar

Sari, Norma. (2014). Pemberdayaan Hak Konsumen atas Informasi Obat. Jurnal Media Hukum, 21(2), 16. Google Scholar

Smith, D., Maharaj, S., \& James, K. (2011). Satisfaction with pharmacy services and its relationships with the control of selected chronic diseases. West Indian Medical Journal, 60(3), 293. Google Scholar

Sriatmi, Ayun, Suryawati, Chriswardani, \& Hidayati, Aulia Nur. (2014). Analisis Hubungan Karakteristik Pasien dengan Kepuasan Pelayanan Rawat Jalan Semarang Eye Center (SEC) Rumah Sakit Islam Sultan Agung Semarang. Jurnal Kesehatan Masyarakat Universitas Diponegoro, 2(1), 18333. Google Scholar

Supartiningsih, Solichah. (2017). Kualitas pelayanan kepuasan pasien rumah sakit: kasus pada pasien rawat jalan. Jurnal Medicoeticolegal Dan Manajemen Rumah Sakit, 6(1), 9-15. Google Scholar

Winanto, Aris. (2013). Persepsi konsumen terhadap pelayanan apotek di kota Ranai kecamatan Bunguran Timur kabupaten Natuna. Jurnal Mahasiswa Farmasi Fakultas Kedokteran UNTAN, 1(1). Google Scholar

Yuniar, Yuyun, \& Handayani, Rini Sasanti. (2016). Kepuasan Pasien Peserta Program Jaminan Kesehatan Nasional terhadap Pelayanan Kefarmasian di Apotek. Jurnal Kefarmasian Indonesia, 39-48. Google Scholar

\section{Copyright holder:}

Elza Rachman Panca Priyanda, Oktri Lestari, Riri Amanda Fitriana, Futri handayani, Ayu Dwi Utami (2021)

\section{First publication right:}

Syntax Idea

\section{This article is licensed under:}

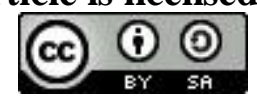

